Kansas State University Libraries

New Prairie Press

\title{
COMPARING LINEAR MIXED MODELS FOR PRELIMINARY YIELD TRIALS THAT FOLLOW AUGMENTED EXPERIMENTAL DESIGNS
}

Sudha Neupane Adhikari

South Dakota State University, sudha.neupaneadhikari@sdstate.edu

Jixiang Wu

South Dakota State University, jixiang.wu@sdstate.edu

Melanie Caffe

South Dakota State University, melanie.caffe@sdstate.edu

Follow this and additional works at: https://newprairiepress.org/agstatconference

Part of the Agriculture Commons, and the Applied Statistics Commons

\section{(c) (1) $\Theta($}

This work is licensed under a Creative Commons Attribution-Noncommercial-No Derivative Works 4.0 License.

\section{Recommended Citation}

Neupane Adhikari, Sudha; Wu, Jixiang; and Caffe, Melanie (2016). "COMPARING LINEAR MIXED MODELS FOR PRELIMINARY YIELD TRIALS THAT FOLLOW AUGMENTED EXPERIMENTAL DESIGNS," Conference on Applied Statistics in Agriculture. https://doi.org/10.4148/2475-7772.1472

This Event is brought to you for free and open access by the Conferences at New Prairie Press. It has been accepted for inclusion in Conference on Applied Statistics in Agriculture by an authorized administrator of New Prairie Press. For more information, please contact cads@k-state.edu. 


\title{
COMPARING LINEAR MIXED MODELS FOR PRELIMINARY YIELD TRIALS THAT FOLLOW AUGMENTED EXPERIMENTAL DESIGNS
}

\author{
Sudha Neupane Adhikari, Jixiang Wu, and Melanie Caffe-Treml \\ Agronomy, Horticulture, and Plant Science Department, \\ South Dakota State University, Brookings, SD 57007
}

Abstract

Ineffective control of spatial variation when analyzing field trials data may lead to biased conclusions, which in turn could impact selection efficiency in plant breeding programs. In this study, a group of 78 oats breeding lines were evaluated in preliminary yield trials at four locations in South Dakota in 2015. Four linear mixed models (with and without row and column effects) were compared regarding reduction in error variance, heritability, and model relative efficiency for three traits (grain yield, test weight, and heading date). Results showed that accounting for row and column effects in the model was effective in reducing error variance and thus improved heritability and model relative efficiency for grain yield and heading date. Inclusion of row and column effects in the statistical models reduced the error variance by $20 \%$ and $14 \%$ for grain yield and heading date, respectively. For test weight, there was $11 \%$ reduction in error variance when only row effect was included in the model suggesting the absence of column effect. Results suggests that for traits affected by spatial trends, the inclusion of row and column effects in statistical models should improve the selection efficiency.

Key Words: augmented experimental design, linear mixed model approaches, variance components, and error variance.

\section{Introduction}

In plant breeding, accurate prediction of genetic values is necessary for genetic gain. Successful selection requires appropriate data analysis to be performed (Wu et al., 2013). Analysis of early generation breeding lines often involves a large set of genotypes (Bondalapati et al. 2014) and a limited quantity of seed, as a result, field trials may be unreplicated. In such situations, augmented designs are commonly used (Kehel et al., 2010; Peternelli \& De Resende, 2015). In unreplicated augmented design, standard or check lines are replicated for controlling experimental error (Santos et al. 2002). However, spatial variation within locations might exist because of different factors like moisture gradient in the soil and variation in soil physical and chemical properties such as pH and fertility (Scharf \& Alley, 1993; Adhikari et al., 1999; Wu \& Dutilleul, 1999; Stroup, 2002). As a result, residual variation may be increased (Stroup, 2002; Wu et al., 2013) leading to biased estimation of genetic effects (Bondalapati et al. 2015). Moreover, as block size increases, the precision in estimating residual variation could decrease (Aragaw, 2011). Thus, emphasis should be given to the development of appropriate methods/models which could reduce the error variance for large field experiments without replications. The selection of an appropriate statistical model plays an important role in increasing precision in estimated results (El-Mohsen, 2013). According to Santos et al. (2002), linear mixed model approach is one of the novel approaches to analyzing augmented experimental designs. Both row and column effects can be included in the 
model and residual variance can be reduced accordingly (Wu et al., 2013). Linear mixed model approach can also be used for analysis of unbalanced data. Three different methods can be used to estimate variance components and predict random effects: maximum likelihood (ML), restricted maximum likelihood (REML), and minimum norm quadratic unbiased estimation (MINQUE) (Hartley and Rao, 1967; Patterson and Thompson, 1971; Rao, 1971; Searle et al., 2009). Although REML has been widely used and is the most popular approach, MINQUE approach is comparable to REML in terms of bias, testing power and Type I error. In comparison to REML, MINQUE approach present several advantages: the computational time for the MINQUE package is less intensive (Nan et al., 2016), and the assumption of normal distribution of the data, and iteration are not required for precise results (Rao, 1971). MINQUE package (Wu 2014) is also integrated with a jackknife technique (a resampling technique) in order to test the significance of parameters (Wu et al., 2008; Wu et al., 2013) and this integration have been found useful for reducing standard error of estimated variance components thus raising the statistical power (Nan et al., 2016).

This study aimed at improving statistical analysis of oat preliminary yield trials that followed an augmented design. The study was based upon one year of field experimental data from 78 genotypes grown at four locations in South Dakota in 2015. Four different linear mixed models or designs were compared using MINQUE approach. Our objectives were to: 1) evaluate if there was presence of spatial trends (row and column effect) and 2) determine which statistical model was best at minimizing error variance for three traits (grain yield, test weight, and heading date).

\section{Materials and methods}

In this study, data was obtained from the preliminary yield trials conducted in 2015 at four South Dakota locations; South Shore $\left(45^{\circ} 6^{\prime} 18^{\prime \prime} \mathrm{N}\right.$ and $\left.96^{\circ} 55^{\prime} 41^{\prime \prime} \mathrm{W}\right)$, Beresford $\left(43^{\circ} 4^{\prime} 51^{\prime \prime} \mathrm{N}\right.$ and

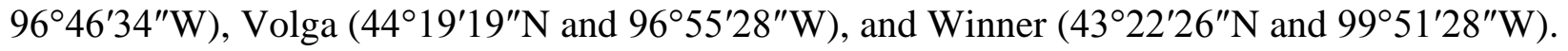
The experimental design for this study was an augmented design, which included 75 breeding lines and three checks (Horsepower, Hayden, and Shelby 427). Each location consisted of 90 plots with checks replicated three times. There were rectangular arrangements with six columns and fifteen rows in South Shore and Beresford, five columns and eighteen rows in Volga, and eight columns and eleven rows in Winner. The plot size was 5 by 6 feet in all locations except for Winner where it was 5 by 13 feet. Data were collected for three agronomic traits: grain yield, test weight, and heading date.

\subsection{Statistical Models}

Based on the field layout, we proposed the following four statistical models for data analysis in this study.

Model 1: most reduced model

$\mathrm{y}=\mu+\mathrm{L}+\mathrm{G}+\mathrm{e}$

Model 2: including row effect

$\mathrm{y}=\mu+\mathrm{L}+\mathrm{G}+\mathrm{R}: \mathrm{L}+\mathrm{e}$

Model 3: including column effect

$y=\mu+L+G+C: L+e$

Model 4: full model including row and column effects

$y=\mu+L+G+R: L+C: L+e$ 
Where, $\mathrm{y}$ is an observation; $\mu$ is the population mean; $\mathrm{L}$ is a location effect; $\mathrm{G}$ is a genotypic effect; $\mathrm{R}$ : $\mathrm{L}$ is a row effect nested in location; $\mathrm{C}$ : $\mathrm{L}$ is a column effect nested in location, and e is random error. Among these four models, model 1 is the most reduced model without row or column effect; model 2 includes row effect; model 3 includes column effect; and model 4 includes both row and column effects and is considered as a full model in this study.

We treated all components except the population mean in these four models as random.

Data were analyzed with those four different statistical models using a linear mixed model approach integrated with jackknife resampling technique available on the $\mathrm{R}$ package, MINQUE (Wu, 2014). We randomly divided 20 groups for the jackknife process due to non-replicated field plots.

To compare the different models, broad sense heritability and relative efficiency were computed as follow:

Variance due to genotype $\left(V_{G}\right)$

Broad sense heritability $\left(\mathrm{H}^{2}\right)=\frac{}{\text { Variance due to genotype }\left(V_{G}\right)+\text { Variance due to error }\left(V_{e}\right)}$

Error variance of most reduced model

Relative Efficiency (R.E) $=\overline{\text { Error variance of model with row/and column effect }}$

The greater the value of heritability and relative efficiency for a model, the more efficient the model is considered.

\section{Results}

Data for three agronomic traits (grain yield, test weight, and heading date) were collected from four locations (Table 1). Grain yield ranged from $27.35 \mathrm{bu} / \mathrm{a}$ to $222.5 \mathrm{bu} / \mathrm{a}$. Test weight ranged from $21.40 \mathrm{lb} / \mathrm{bu}$ to $43.65 \mathrm{lb} / \mathrm{bu}$. A variation of 25 days was recorded between the earliest heading date and the latest. Both genotype and location had an effect on the three traits.

Table 1. Summary of the agronomic data collected at four South Dakota locations for oat genotypes evaluated in preliminary yield trials, 2015

\begin{tabular}{lcccccccccccc}
\hline Locations & \multicolumn{4}{c}{ Yield (bu/ac) } & \multicolumn{4}{c}{ Test weight (lb/bu) } & \multicolumn{4}{c}{ Heading date $^{\mathbf{1}}$} \\
\hline & Mean & Variance & \multicolumn{2}{c}{ Range } & Mean & Variance & Range & Mean & Variance & Range \\
South Shore & 145.8 & 721.4 & 88.85 & 222.5 & 37.39 & 3.44 & 30.15 & 40.69 & 166.7 & 5.99 & 163 & 173 \\
Beresford & 150.8 & 463.2 & 100.4 & 196.5 & 36.99 & 4.35 & 29.84 & 43.65 & 159.0 & 3.19 & 155 & 163 \\
Volga & 106.4 & 733.9 & 47.93 & 169.5 & 31.52 & 11.83 & 21.40 & 37.45 & 180.0 & 2.36 & 176 & 183 \\
Winner & 73.22 & 231 & 27.35 & 117.8 & 40.08 & 1.09 & 37.79 & 42.78 & 161.2 & 3.27 & 158 & 167 \\
\hline
\end{tabular}

\footnotetext{
${ }^{1}$ Heading date: Julian Calendar date (when half of the inflorescence has emerged)
} 


\subsection{Spatial variation in field trials}

Residuals of grain yield for the four models (1-4) were calculated through MINQUE analysis and are presented in the field layout pattern for the Winner location (Figure 1). Among the four different models, range of residuals was highest for model 1 suggesting the presence of higher spatial variation which was followed by model 2 and model 3. In model 4 the range in residuals was almost half when compared to model 1. Reduction in the residuals in model 4 was due to inclusion of row and column effects. Gradients in both rows and columns are visible on the heat map (Figure 1). Although not presented here, similar variation was observed in the other three locations.

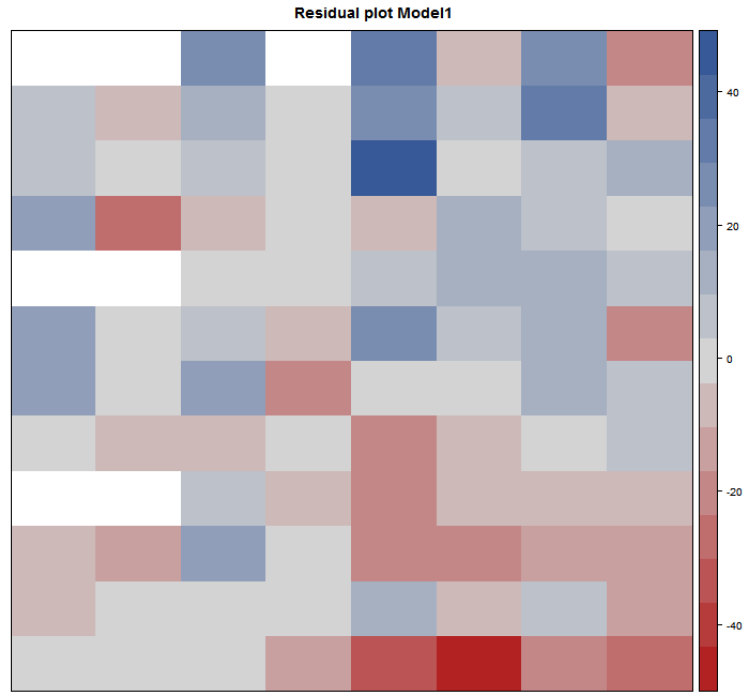

(a)

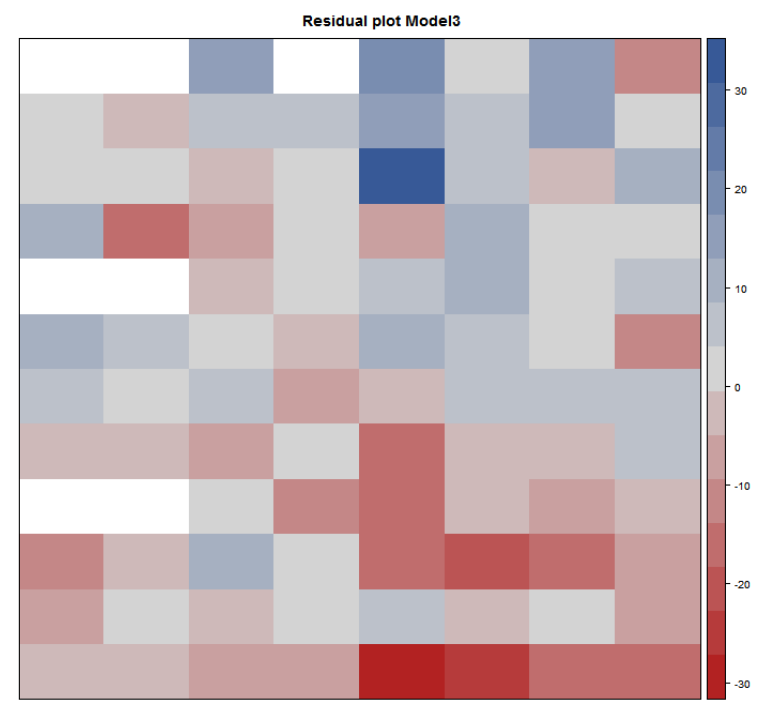

(c)

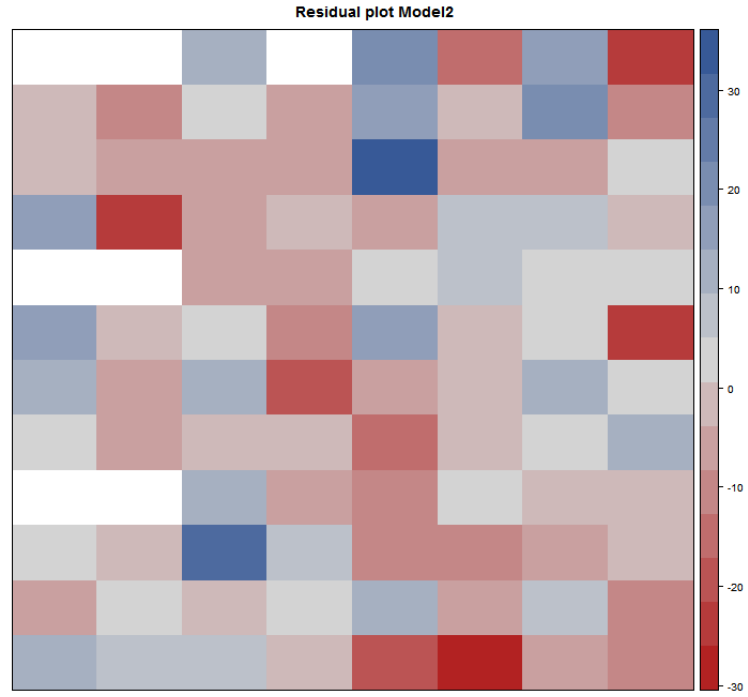

(b)

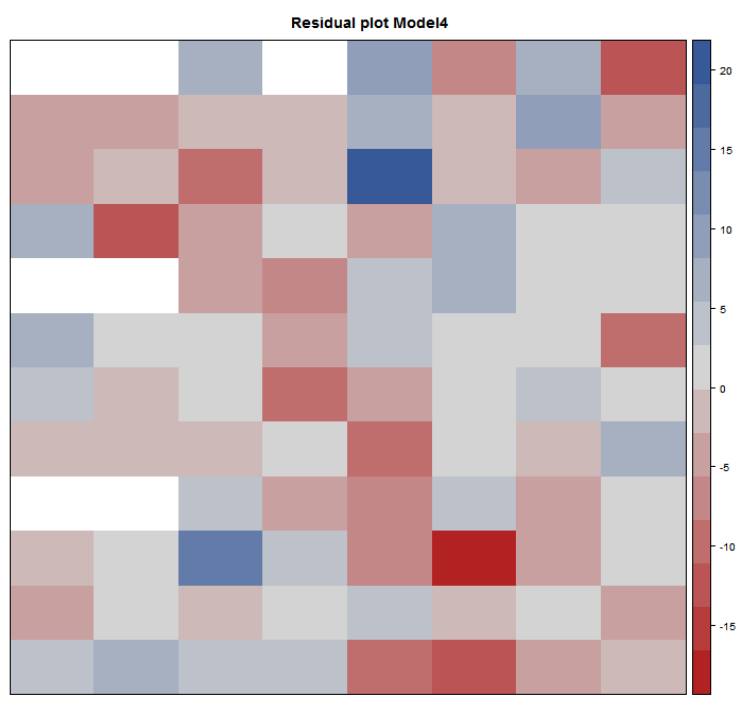

(d) 
Figure 1. Heat map of residuals for grain yield in Winner, SD using four different models; Model 1 (a): most reduced model, Model 2 (b): includes row effect, Model 3 (c) : includes column effect, and Model 4 (d) : includes both row and column effects.

\subsection{Estimated variance components}

Estimated variance components obtained for four different models (described in materials and methods) are listed in Table 2. Results showed that, row and column effects were significant for grain yield and heading date. For test weight, only row effect was significant. Although, variance contributed by row and column effects was lower than variance due to location and genotypes in all models, there was a decrease in error variance when row and column effects were included (Table 2 and Figure 2). This finding was in agreement with another study (Bondalapati et al. 2015). The error variance $\left(V_{e}\right)$ decreased by $20 \%$ for yield, $11 \%$ for test weight, and $14 \%$ for heading date (Table 2) by including row and column effects. Based on the estimated error variances from different models, model 4 (full model) was either more efficient or comparable to the other models depending on the traits (Figure 2). Row effect was significant for all traits while column effect was not significant for test weight. Using models with either row and/or column effect, the heritability increased from 0.31 to $0.37,0.35$ to 0.37 , and 0.63 to 0.66 as compared to the reduced model for yield, test weight, and heading date, respectively. Furthermore, the effectiveness of models with row and column effects was supported by the increased relative efficiency of the full model in comparison to most reduced model (Table 2).

Table 2. Estimated variance components for four statistical models for grain yield, test weight and heading dates for the oat preliminary yield trials, 2015.

\begin{tabular}{|c|c|c|c|c|c|c|c|c|c|c|c|c|}
\hline Parameter & \multicolumn{4}{|c|}{ Grain Yield } & \multicolumn{4}{|c|}{ Test Weight } & \multicolumn{4}{|c|}{ Heading Date } \\
\hline & Model1 & Model2 & Model3 & Model4 & Model1 & Model2 & Model3 & Model4 & Model1 & Model2 & Model3 & Model4 \\
\hline$V_{L}$ & $1313^{* * *}$ & $1291^{* * *}$ & $1347^{* * *}$ & $1323^{* * *}$ & $13.06^{\text {**** }}$ & $13.11^{\text {**** }}$ & $12.80^{* * * *}$ & $12.85^{* * * *}$ & $88.97^{* * *}$ & $90.07^{* * *}$ & $85.92^{* * * *}$ & $86.99^{* * *}$ \\
\hline$V_{G}$ & $161.2^{* * *}$ & $171.5^{* * *}$ & $157.0^{* * * *}$ & $165.9^{* * * *}$ & $1.63^{* * * *}$ & $1.56^{* * *}$ & $1.64^{* * *}$ & $1.55^{* * *}$ & $2.28^{* * * *}$ & $2.24^{* * * *}$ & $2.32^{* * * *}$ & $2.23^{* * * *}$ \\
\hline$V_{R(L)}$ & & $23.27^{* *}$ & - & $31.59^{* * *}$ & - & $0.39^{* * *}$ & - & $0.35^{* * *}$ & - & $0.17^{* * *}$ & - & $0.17^{* *}$ \\
\hline$V_{C(L)}$ & - & - & $47.15^{* * *}$ & $49.28^{* * *}$ & - & - & 0.0 & 0.0 & - & - & $0.19^{* * *}$ & $0.18^{* * * *}$ \\
\hline$V_{e}$ & $356.1^{* * *}$ & $333.6^{* * *}$ & $317.0^{* * *}$ & $285.4^{* * * *}$ & $3.02^{* * * *}$ & $2.70^{* * * *}$ & $3.11^{* * *}$ & $2.81^{* * * *}$ & $1.34^{* * *}$ & $1.15^{* * *}$ & $1.36^{* * * *}$ & $1.17^{* * * *}$ \\
\hline$H^{2}$ & 0.31 & 0.34 & 0.33 & 0.37 & 0.35 & 0.37 & 0.34 & 0.35 & 0.63 & 0.66 & 0.63 & 0.66 \\
\hline RE & - & 1.07 & 1.12 & 1.25 & - & 1.12 & 0.97 & 1.07 & - & 1.17 & 0.99 & 1.15 \\
\hline
\end{tabular}

*Significant at 0.05 probability, **Significant at 0.01 probability and ***Significant at 0.001 probability.

Model 1: most reduced model, Model2: includes row effect, Model3: includes column effect, and Model4: includes both row and column effects. 


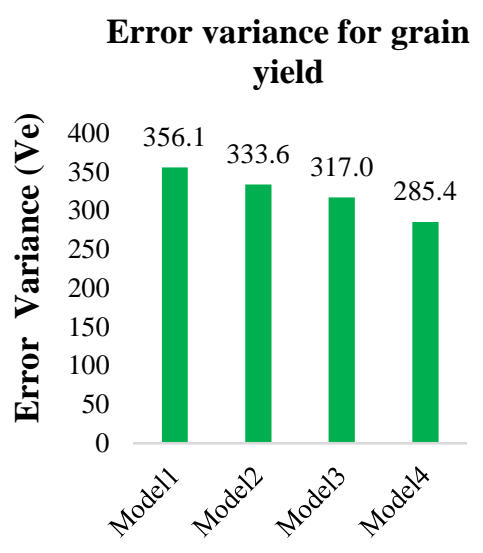

Statistical model

\section{Error variance for test weight}

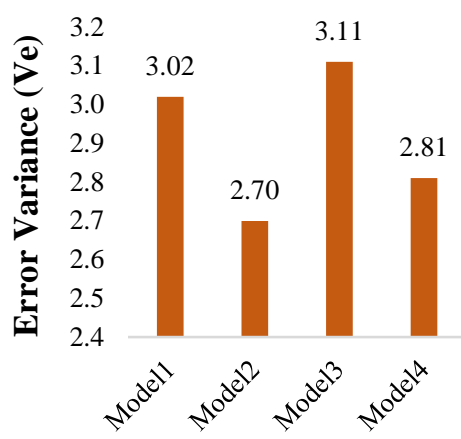

Statistical model
Error variance for heading date

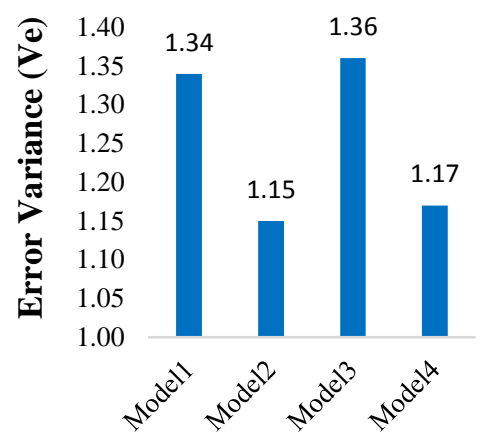

Statistical model

Figure 2. Error variance in different statistical models; Model1: most reduced model, Model2: includes row effect, Model3: includes column effect, and Model4: includes both row and column effects for grain yield, test weight and heading dates for oat genotypes evaluated in preliminary yield trials, 2015.

\section{Summary}

In this study, presence of spatial variation was assessed by looking at the significance of row and column effects. This was followed by the identification of suitable statistical models that have helped in reducing error variance for three different traits; grain yield, test weight, and heading date in an oat trial. For grain yield, range of residuals for model 4 was reduced by almost half that of model 1 when row and column blocking was done (Figure 1) suggesting the effectiveness of statistical models that account for spatial effects. Use of full model (including row and column effects) significantly reduced error variance associated with grain yield. A decrease in error variance led to an increase in heritability and relative efficiency (Table 2). For test weight and heading date, the full model was comparable to model 2 (with row effect). For test weight, including both row and column effects did not increase heritability and relative efficiency. This result suggests that the best model will depend on the presence/absence of spatial trends and on how a specific trait is affected by those trends.

AIC (Akaike Information Criterion), which is commonly used for model comparison (Wagemakers and Farrell, 2004), was obtained using the lme4 package (Douglas et al., 2015). A lower AIC value is considered as a good model (Mazerolle, 2004). Numerically, our results showed that model 4 was preferable for yield, model 2 and model 4 performed equally well for test weight, and model 2 was best for heading date. However, as expected, these AIC values were similar due to small row and/or column effect. In this study, we used error variance, heritability and relative efficiency to compare these models, which yielded similar conclusions.

Findings from this study suggested that statistical models can be an important tool to address spatial variations. By accounting for the spatial trends present in the field, analysis of phenotypic 
data can be improved. Similar findings were obtained in a upland cotton yield trial (Bondalapati et al. 2015), wheat breeding trials (Qiao et al., 2001), and forestry field experiment (Hamann et al., 2002). Results from this study as well as the above-mentioned studies show the significance of statistical models to reduce error variance, and to ultimately increase genetic gain.

\section{Acknowledgement}

The authors wish to thank the South Dakota Agricultural Experimental Station for support. This material is based upon work that is partially supported by the National Institute of Food and Agriculture, U.S. Department of Agriculture, under award number 2016-67014-24466 and 1005459. Any opinions, findings, conclusions, or recommendations expressed in this publication are those of the authors and do not necessarily reflect the view of the U.S. Department of Agriculture.

\section{References}

Adhikari, C., Bronson, K. F., Panuallah, G. M., Regmi, A. P., Saha, P. K., Dobermann, A., Olk, D.C., Hobbs, P.R. \& Pasuquin, E. (1999). On-farm soil N supply and N nutrition in the rice-wheat system of Nepal and Bangladesh. Field Crops Research, 64(3), 273-286.

Araagaw, E. (2011). Construction and analysis of augmented and modified augmented designs (Doctoral dissertation, aau) http://hdl.handle.net/123456789/226

Bondalapati, K. D., Jenkins, J. N., McCarty, J. C., \& Wu, J. (2015). Field experimental design comparisons to detect field effects associated with agronomic traits in upland cotton. Euphytica, 206(3), 747-757.

Bondalapati, K. D., Wu, J., \& Glover, K. D. (2014). An augmented additive-dominance (AD) model for analysis of multi-parental spring wheat F2 hybrids. Australian Journal of Crop Science, 8(10), 1441-1447.

Douglas Bates, Martin Maechler, Ben Bolker, Steve Walker (2015). Fitting Linear Mixed-Effects Models Using lme4. Journal of Statistical Software, 67(1), 1-48.<doi:10.18637/jss.v067.i01>.

El-Mohsen, A. A., \& Abo-Hegazy, S. R. (2013). Comparing the relative efficiency of two experimental designs in wheat field trials. Sci. Res. Review J., 1, 101-109.

Hamann, A., Namkoong, G., \& Koshy, M. P. (2002). Improving precision of breeding values by removing spatially autocorrelated variation in forestry field experiments. Silvae Genetica, 51(56), 210-215.

Hartley, H. O., \& Rao, J. N. (1967). Maximum-likelihood estimation for the mixed analysis of variance model. Biometrika, 54(1-2), 93-108. 
Kehel, Z., Habash, D. Z., Gezan, S. A., Welham, S. J., \& Nachit, M. M. (2010). Estimation of spatial trend and automatic model selection in augmented designs. Agronomy journal, 102(6), 1542-1552.

Mazerolle, M. J. (2004). Making sense out of Akaike's Information Criterion (AIC): its use and interpretation in model selection and inference from ecological data. \& http://www. theses. ulaval. ca/2004/21842/apa. html.

Nan, N., Jenkins, J. N., McCarty, J. C., \& Wu, J. (2016). Comparison of REML and MINQUE for Estimated Variance Components and Predicted Random Effects. Open Journal of Statistics, 6(05), 814.

Patterson, H. D., \& Thompson, R. (1971). Recovery of inter-block information when block sizes are unequal. Biometrika, 58(3), 545-554.

Peternelli, L. A., \& de Resende, M. D. V. (2015). Experimental designs for next generation phenotyping. In Phenomics (pp. 15-32). Springer International Publishing.

Qiao, C. G., Basford, K. E., DeLacy, I. H., \& Cooper, M. (2000). Evaluation of experimental designs and spatial analyses in wheat breeding trials. Theoretical and Applied Genetics, 100(1), 916.

Rao, C. R. (1971). Estimation of variance and covariance components-MINQUE theory. Journal of multivariate analysis, 1(3), 257-275.

Santos, A. H., Bearzoti, E., Ferreira, D. F., \& Silva Filho, J. L. D. (2002). Simulation of mixed models in augmented block design. Scientia Agricola, 59 (3), 483-489.

Scharf, P. C., \& Alley, M. M. (1993). Accounting for spatial yield variability in field experiments increases statistical power. Agronomy Journal, 85(6), 1254-1256.

Searle, S. R., Casella, G., \& McCulloch, C. E. (2009). Variance components (Vol. 391). John Wiley \& Sons.

Stroup, W. W. (2002). Power analysis based on spatial effects mixed models: a tool for comparing design and analysis strategies in the presence of spatial variability. Journal of agricultural, biological, and environmental statistics, 7(4), 491-511.

Wagenmakers, E. J., \& Farrell, S. (2004). AIC model selection using Akaike weights. Psychonomic bulletin \& review, 11(1), 192-196.

Wu, T., \& Dutilleul, P. (1999). Validity and efficiency of neighbor analyses in comparison with classical complete and incomplete block analyses of field experiments. Agron. J. 91:721-731. doi:10.2134/agronj1999.914721x 
Wu, J., Jenkins, J. N., and McCarty, J. C. (2010). " Testing variance components by two jackknife methods," Annual Conference on Applied Statistics in Agriculture.

http://newprairiepress.org/agstatconference/2008/proceedings/2

Wu, J., Jenkins, J. N., and McCarty, J. C. (2010). " A generalized approach and computer tool for quantitative genetics study," Annual Conference on Applied Statistics in Agriculture. http://newprairiepress.org/ agstatconference/2010/proceedings/7

Wu, J., Bondalapati, K., Glover, K., Berzonsky, W., Jenkins, J. N., \& McCarty, J. C. (2013). Genetic analysis without replications: model evaluation and application in spring wheat. Euphytica, 190(3), 447-458.

Wu J (2014) minque: An R package for linear mixed model analyses. 1.1 edn, http://cran.rproject.org/ 